Kumawula, Vol. 2, No.2, Agustus 2019, Hal 163 - 174 DOI:http://10.24198/kumawula.v1i3.24391

ISSN 2620-844X (online)

Tersedia online di http://jurnal.unpad.ac.id/kumawula/index

\title{
Sosialisasi Pengenalan Revolusi Industri 4.0 dan Internet of Things (IoT) Bagi Siswa SMAN 1 Cicalengka, Jawa Barat, Indonesia
}

\author{
Dudy Heryadi ${ }^{1}$, M. Benny Alexandri ${ }^{2}$, Deasy Silvya Sari ${ }^{3 *}$ \\ ${ }^{1}$ Departemen Hubungan Internasional, Fakultas Ilmu Sosial dan Ilmu Politik, Universitas Padjadjaran \\ ${ }^{2}$ Departemen Administrasi Bisnis, Fakultas Ilmu Sosial dan Ilmu Politik, Universitas Padjadjaran \\ ${ }^{3}$ Departemen Hubungan Internasional, Fakultas Ilmu Sosial dan Ilmu Politik, Universitas Padjadjaran \\ *deasy.silvya@unpad.ac.id
}

\begin{abstract}
ABSTRAK
Artikel ini bertujuan memaparkan kegiatan pengabdian pada masyarakat (PPM) yang terinterasi dengan kegiatan Kuliah Kerja Nyata Mahasiswa (KKNM) Universitas Padjadjaran dalam semester ganjil 2019 di SMAN 1 Cicalengka berupa sosialisasi mengenai pengenalan Revolusi Industri 4.0 dan Internet of Things (IoT). Metode yang dilakukan adalah eksperimen dengan mengajak para siswa untuk ikut berperan aktif dalam kegiatan sosialisasi. Selain mendengarkan materi sosialisasi, para siswa melakukan simulasi mengenai keterampilan-keterampilan sederhana terkait IoT. Hasil dari kegiatan ini menunjukkan bahwa siswa SMAN 1 Cicalengka telah mengetahui mengenai Revolusi Industri 4.0 dan tantangan yang akan dihadapi. Internet of Things (IoT) yang diperkenalkan adalah artificial intelligence (AI), esport, dan Youtube.
\end{abstract}

Kata Kunci: Internet of Things (IoT), Revolusi Industri 4.0, SMAN 1 Cicalengka

\section{Socializing the Industrial Revolution 4.0 and Internet of Things (IoT) for the Students of SMAN 1 Cicalengka, Jawa Barat, Indonesia}

\begin{abstract}
This article aims to describe a program of Pengabdian Pada Masyarakat (PPM) integrated with Kuliah Kerja Nyata Mahasiswa (KKNM) Universitas Padjadjaran in the first semester of 2019 in SMAN 1 Cicalengka in the form of a socialization about the introduction of Industrial Revolution 4.0 and Internet of Things (IoT). The program used the experiment method that required students to participate and contribute actively in the socialization program. Besides hearing about the socialization materials, students did simulations about simple skills of IoT. The results of this program shows that the students of SMAN 1 Cicelangka have known about Industrial Revolution 4.0 and it's challenges. The Iot that was introduced in this program were artificial intelligence (AI), eSport, and youtube.
\end{abstract}

Keywords: Industrial Revolution 4.0, Internet of Things (IoT), SMAN 1 Cicalengka

\section{PENDAHULUAN}

Revolusi industri 4.0 merupakan sebuah istilah yang sedang ramai dibicarakan saat ini. Revolusi industri adalah periode waktu dimana pekerjaan mulai lebih banyak dilakukan 
dengan mesin daripada dengan tangan di rumah (Belvedere dalam (Liao, Loures, Deschamps, Brezinski, \& Venancio, 2018, hal. 1). Saat ini, industri telah memasuki tahap revolusi 4.0 berupa berbagai perubahan yang berlangsung dalam bidang industri. Revolusi Industri merupakan sebuah revolusi yang mungkin berlangsung karena penerapan teknologi canggih pada level produksi yang membawa nilai-nilai dan jasa-jasa baru bagi pelanggan dan organisasi itu sendiri (Khan \& Turowski, 2016, hal. 442).

Sebelum berlangsung revolusi industri 4.0, bidang industri telah mengalami revolusi pertama, kedua dan ketiga (Nugraha, 2018, hal. 2) (Rojko, 2017, hal. 79). Revolusi Industri 1.0 berlangsung akhir abad 18 yang mendorong peningkatan kualitas hidup melalui proses mekanisasi terutama dipicu dengan penemuan tenaga air dan tenaga uap. Revolusi Industri 2.0 berlangsung pada awal abad 20 yang mendorong produksi massal kelistrikan dengan berlangsungnya elektrifikasi dan industrialisasi. Revolusi Industri 3.0 berlangsung awal tahun 1960an yang mendorong mikro elektronik dan produksi yang fleksibel berupa digitalisasi, dan automatisasi elektronik. Revolusi Industri 4.0 berlangsung saat ini yang mendorong produksi massa berbasis teknologi komputer dan informasi berupa sistem fisik siber dan automatisasi 'cerdas'.

Revolusi Industri 4.0 mau tidak mau akan mempengaruhi gaya hidup umat manusia. Menurut (Morra, Arman, \& Mousa, 2017, hal. 18), revolusi Industri 4.0 memiliki sisi buruk berupa pengangguran, pergantian tenaga manusia oleh inovasi teknologi, hilangnya privasi individu, dan hilangnya kontrol manusia. Namun, daripada fokus pada sisi-sisi buruk Revolusi Industri 4.0 alangkah lebih baik jika manusia dapat beradaptasi dengan melakukan inovasi-inovasi sosial. Salah satu contohnya adalah membentuk lingkungan virtual dimana orang dan teknologi yang sedang berkembang mampu berinteraksi dan berperilaku secara natural. Inovasi sosial merupakan kreativitas yang memperhatikan aspek berkelanjutan dalam menciptakan produk melalui proses dan metode yang mampu memberikan solusi bagi masyarakat. Inovasi sosial menggabungkan teknologi dan model bisnis serta menghasilkan nilai-nilai bersama dengan melibatkan berbagai stakeholders, seperti: perusahaan, pemerintah, social enterprises, lembaga swadaya masyarakat (LSM), dan pihak lainnya (Ayu, 2018, hal. $3)$.

Revolusi Industri menyuguhkan berbagai tantangan yang harus dihadapi. Tantangan mendasar yang menjadi inti dari revolusi industri 4.0 adalah keamanan siber (Morra, Arman, \& Mousa, 2017, hal. 13). Potensi tantangan revolusi industri 4.0 adalah pengangguran, penguasaan 
keterampilan, tantangan infrastruktur terutama infrastruktur yang mampu mendukung perkembangan teknologi informatika, serta keamanan dan privasi (Manda \& Dhaou, 2019, hal. 247). Revolusi industri 4.0 yang seyogyanya berlangsung dalam aspek teknologi, ternyata menimbulkan perubahan sosial yang memberikan tantangan tersendiri. Guna menyikapi tantangan sosial yang berlangsung, diperlukan pelaksanaan pendidikan yang cocok dan saling terhubung antara manusia dengan kebutuhan dalam era revolusi industri dan perlunya penyiapan sumber daya manusia yang dibekali dengan nilai-nilai kemanusiaan seperti yang diajarkan alam ilmu sosial humaniora (Prasetyo \& Trisyanti, 2018, hal. 26).

Menghadapi tantangan dalam era revolusi industri, tim Pengabdian Pada Masyarakat terintegrasi KKNM Unpad memandang perlu adanya sebuah pengenalan awal bagi para pemuda mengenai Revolusi Industri 4.0. Di satu sisi, revolusi industri 4.0 dapat menggerus para pemuda bangsa Indonesia, khususnya, manakala mereka tidak mampu beradaptasi dengan perubahan yang berlangsung, atau hanya menjadi konsumen dari berbagai produk inovasi revolusi industri 4.0. Di sisi lain, tim PPM terintegrasi KKNM Unpad menyadari pula bahwa berbagai perubahan yang berlangsung dalam revolusi industri 4.0 adalah sebuah takdir. Hanya, bagaimana menghadapi takdir perubahan tersebut? Tentunya dibutuhkan persiapan yang cukup matang dan strategi yang apik dalam menghadapi perubahan.

Untuk itu, tim PPM terintegrasi KKNM Unpad melakukan kegiatan berupa sosialisasi mengenai Revolusi Industri 4.0 dan Internet of Things (IoT), khususnya, tentang AI (Artificial Intelligence), e-sport dan youtubers dengan sasaran para pemuda, khususnya siswa di SMAN 1 Cicalengka. Artikel ini bertujuan memaparkan pelaksanaan dan hasil dari kegiatan sosialisasi tersebut.

\section{TINJAUAN PUSTAKA}

\section{Revolusi Industri 4.0}

Konsep industri 4.0 awalnya berasal dari pemerintah Jerman sebagai sebuah inisiatif strategis pembangunan sektor industri berupa keberlanjutan posisi Jerman sebagai salah satu negara yang paling berpengaruh dalam bidang permesinan dan otomotif manufaktur. Jerman memperkenalkan konsep ini pertama kali dalam acara Hannover Fair 2011. Gagasan utama industri 4.0 yang diusung Jerman adalah pemanfaatan potensi teknologi dan konsep baru mengenai: (i) ketersediaan dan penggunaan internet dan Internet of Things (IoT); (ii) integrasi proses teknis dan proses bisnis dalam perusahaan-perusahaan; (iii) pemetaan digital dan 
virtualisasi dunia nyata; dan (iv) pabrik 'cerdas' termasuk alat produksi industri dan produk 'cerdas' (Rojko, 2017, hal. 80). Di Amerika Serikat, industri 4.0 dikenal dengan 'Connected Enterprise' dan di Inggris dikenal dengan 'Fourth Industrial Revolution' (Morra, Arman, \& Mousa, 2017).

Terdapat beberapa faktor pendorong revolusi Industri 4.0. Pertama, infrastruktur informasi dan komunikasi dan teknologi-teknologi yang sedang muncul. Dalam hal ini, internet dan teknologi pendukungnya menjadi ciri khas dari revolusi industri 4.0 karena mampu menyediakan konektivitas digital dan menghasilkan sebuah sistem siber-fisikal. Dalam menghadapi sistem ini diperlukan kecerdasan dalam memanfaatkan penggunaan Big Data agar mampu menjaga efisiensi dan efektivitas pada saat membuat berbagai keputusan. Kedua, pendidikan dan pelatihan. Era revolusi industri 4.0 menimbulkan rasa kekhawatiran akan tergantikannya tenaga kerja manusia oleh mesin. Terlebih, ada pula asumsi bahwa dalam era revolusi industri akan berlangsung robotisasi manusia, dimana hati dan jiwa manusia akan tergerus dalam mekanisasi rutinitas. Kekhawatiran ini wajar muncul. Hanya saja, perubahan dalam hidup adalah takdir yang harus dihadapi. Untuk menghadapi berbagai tantangan dalam revolusi industri 4.0 dibutuhkan pendidikan yang mampu mengembangkan sisi kemanusiaan manusia (baik itu inovasi, kreativitas, empati, kesadaran, moralitas, dan sebagainya) dan pelatihan guna meningkatkan keterampilan. Keterampilan pada dasarnya diperlukan untuk beradaptasi dengan perkembangan teknologi yang kian pesat. Ketiga, inovasi. Revolusi industri 4.0 menuntut daya inovasi yang tinggi dari sisi produksi, model-model bisnis dan teknik-teknik produksi yang memanfaatkan teknologi. Keempat, inovasi kebijakan. Revolusi industri 4.0 menuntut pemerintah suatu negara untuk mengeluarkan kebijakan-kebijakan yang mampu mendukung perkembangan teknologi yang berlangsung dinamis, terutama yang berkaitan dengan keterampilan, infrastruktur, pendanaan, regulasi, dan sebagainya. Kelima, strategi yang responsif dan spesifik yang mampu memenuhi tuntutan digitalisasi, konektivitas, dan lingkungan (Manda \& Dhaou, 2019, hal. 246-247).

Menghadapi tuntutan tersebut, terdapat beberapa kebijakan inovatif yang dapat dilakukan guna mengimbangi perubahan dalam revolusi industri 4.0. Pertama, pengenalan sistem. Perlu disadari bahwa industri 4.0 merupakan sebuah sistem yang dibangun dari interaksi di antara berbagai jejaring (networks) dan aktor. Sebuah sistem tentu memiliki unit (aktor) dan cara kerja (fungsi dari unit). Agar mampu bertahan (survive) dalam revolusi industri 4.0, setiap unit perlu mengenal dan mengetahui posisi dan apa yang harus dilakukan serta memperkuat kompetensi dan kemampuan diri. Kedua, industri 4.0 bukan hanya sekedar high-tech. Esensi 
industri tetap untuk memenuhi kebutuhan konsumen. Industri 4.0 harus mampu memadukan antara inovasi berbasis sains melalui aplikasi-aplikasi dan inovasi berawal dari konsumen guna memenuhi kebutuhan mereka. Ketiga, industri 4.0 mengarah pada progres sosial. Perkembangan itu adalah dari dan untuk manusia: semuanya tentang manusia. Teknologi dikembangkan sebagai sebuah sistem yang mampu membantu agar pekerjaan manusia 'easy to use', mudah dipergunakan. Bagaimana mengembangkan karir, bagaimana berpartisipasi dalam kegiatan sosial, bagaimana memenuhi mereka yang berkebutuhan khusus, bagaimana melakukan kompetisi, bagaimana melakukan perlindungan kekayaan intelektual, ruang dan keamanan privasi, perlindungan data, semua itu merupakan contoh tuntutan teknologi dalam revolusi industri 4.0 yang mampu mendukung progres sosial seseorang. Keempat, industri 4.0 harus dipahami sebagai sebuah inovasi sosial. Inovasi hanya mampu dianggap dan bermakna sosial manakala ia diterima secara sosial, tersebarluas di dalam masyarakat atau kelompok sosial tertentu, dan terlembagakan atau menjadi rutinitas sebagai sebuah praktek sosial baru. Inovasi yang dilakukan dalam industri 4.0 harus menjadi praktek sosial yang sifatnya 'better for people": lebih baik bagi orang-orang. Kelima, industri 4.0 harus tertanam dalam perekonomian pasar terkoordinir. Perekonomian dibagnun di atas 'budaya kerjasama' dengan pola hubungan jangka panjang, berbasis saling percaya di antara pengusaha, pekerja, investor, supplier dan pihak terkait lainnya dengan dukung lembaga pendidikan dan penelitian. Keenam, industri 4.0 bukan hanya tentang mesin, tapi orang. Dalam kultur kerjasama partisipatif, pembelajaran jangka panjang harus didukung melalui pelatihan dan pengembangan karir. Hal ini melibatkan pula bentuk-bentuk kegiatan seperti peningkatan pendanaan bagi universitas dan pengembangan kesempatan karir para akademisi. Ketujuh, industri 4.0 memerlukan perlindungan dan pengamanan data privasi yang lebih baik. Dan kedelapan, industri memerlukan koordinasi kebijakan (Buhr, 2017, hal. 11-14).

\section{METODE}

Metode yang dilakukan dalam kegiatan sosialisasi ini adalah eksperimen. SMAN 1 Cicalengka memberikan kesempatan kepada tim PPM terintegrasi KKNM Unpad untuk mengisi tiga (3) kelas. Masing-masing kelas diisi dengan tiga tema yang berbeda, yakni: satu kelas berupa sosialisasi mengenai artificial intelligence (AI), satu kelas dengan tema e-sport, dan satu kelas lagi dengan tema youtubers.

\section{HASIL DAN PEMBAHASAN}

Sosialisasi dalam Kelas Pertama SMAN 1 Cicalengka: Artificial Intelligence 
Dalam kelas pertama, tim PPM terintegrasi KKNM memberikan sosialisasi mengenai artificial intelligence (AI) atau kecerdasan buatan. Pada tahap pertama, tim KKNM memberikan materi mengenai artificial intelligence. adapun materi yang disampaikan terkait dengan pengertian contoh-contoh AI yang telah diterapkan dalam kehidupan sehari-hari saat ini, dan ide tim KKNM terkait pengembangan ABG (AI Based Government). Tujuan Tim PPM terintegrasi KKNM melakukan simulasi membuat desain artificial intelligence pada para siswa adalah terbersitnya ide-ide inovatif berbasis IT yang dapat dikembangkan untuk kebermanfaatan teknologi dalam kehidupan masyarakat.

Artificial Intelligence (AI) adalah teknologi yang mampu membuat mesin menjadi cerdas dimana mesin tersebut mampu mereplikasi kecerdasan manusia, mampu melakukan analisis dan pengambilan keputusan layaknya manusia (Auditor, 2017, hal. 2). Menurut Berente, dkk (Berente, Gu, Recker, \& Santhanam, 2019, hal. 1), AI adalah mesin yang mampu memperlihatkan fungsi-fungsi kognitif seperti manusia, misalnya melakukan persepsi, mampu memberikan alasan, mampu belajar, berinteraksi dan sebagainya (Berente, Gu, Recker, \& Santhanam, 2019, hal. 1).

Jika AI dibayangkan sangat High-tech, itu adalah benar. Namun, jika AI dibayangkan hanya diperuntukkan bagi kalangan tertentu saja, itu kurang tepat. Pada saat ini, AI sudah diterapkan pada kehidupan sehari-hari. Smartphone telah menggunakan AI dalam fitur-fiturnya, misalnya: pendeteksi sidik jari, wajah, gerakan tangan saat foto, google assistant dan sebagainya. Mesin pencari (engine searching) mampu memberikan saran kata-kata yang mirip yang hendak dicari. Media sosial, layanan streaming, iklan yang tiba-tiba muncul di laman monitor biasanya menyarankan barang-barang yang mungkin menarik karena menawarkan produk-produk berdasarkan kata kunci terakhir yang digunakan. Berbagai aplikasi navigasi dan juga e-commerce (tokopedia, bukalapak, dan sebagainya) juga telah menggunakan AI. Dan terutama, pemakaian AI telah dipergunakan dalam mengembangkan games (Handoyo, 2019).

Pada tahap kedua, para siswa diberi kesempatan untuk melakukan studi literatur mengenai artificial intelligence dan contoh-contoh AI yang sudah diterapkan pada saat ini. Para siswa di kelas pertama SMAN 1 Cicalengka, melihat dari hasil kegiatan KKNM, telah memiliki kemampuan melakukan studi literatur. Misalnya, dengan mempergunakan google para siswa diminta untuk mencari sumber dengan kata kunci tertentu. Pada tahap ketiga, para siswa diberikan kesempatan untuk membuat desain mengenai artificial intelligence yang ingin 
dikembangkan. Desain ini tidak perlu nyata untuk diwujudkan terkait dengan keterbatasan teknologi. Desain ini merupakan sebuah desain impian Artificial intelligence yang nantinya akan mampu memberikan manfaat bagi masyarakat.

\section{Sosialisasi dalam Kelas Kedua SMAN 1 Cicalengka: e-Sport}

e-sport (electronic sport) adalah setiap kegiatan dalam waktu luang yang mempergunakan kemampuan mental dan fisik dalam suatu lingkungan elektronik virtual yang disusun seolaholah dalam dunia nyata (Kim \& Thomas, 2015). E-sport merupakan sebuah arena kegiatankegiatan olahraga dimana orang-orang mengembangkan dan membentuk kemampuan mental dan fisik dengan menggunakan teknologi informasi dan komunikasi Wagner dalam (Huk, 2018, hal. 163).

Istilah esport pertama kali diperkenalkan oleh Online Gamers Association (OGA) tahun 1999. Menjamurnya esport pertama kali dapat ditelusuri dari penyelenggaraan turnamen dunia oleh the World Cyber Games (WCG). Turnamen pertama diselenggarakan tahun 2000 di Seoul, Korea Selatan dengan peserta sebanyak 174 yang berasal dari 17 negara yang tersebar di Eropa Barat dan Timur, Amerika Utara dan Selatan, Asia Pasifik, Oseania, dan Timur Tengah. Tahun 2013, WCG menyelenggarakan turnamen kembali dengan melibatkan 500 peserta dari 38 negara. Kategori yang dilombakan sangat beragam, meliputi: first-person shooters (Counter-Strike), sport (FIFA Soccer), races (Project Gotham Racing and Need for Speed), actions (Virtua Fighter) and strategies (StarCraf, Command and Conquer and Warcraf) (Huk, 2018, hal. 161)

Gambar 1. Sosialisasi E-sport

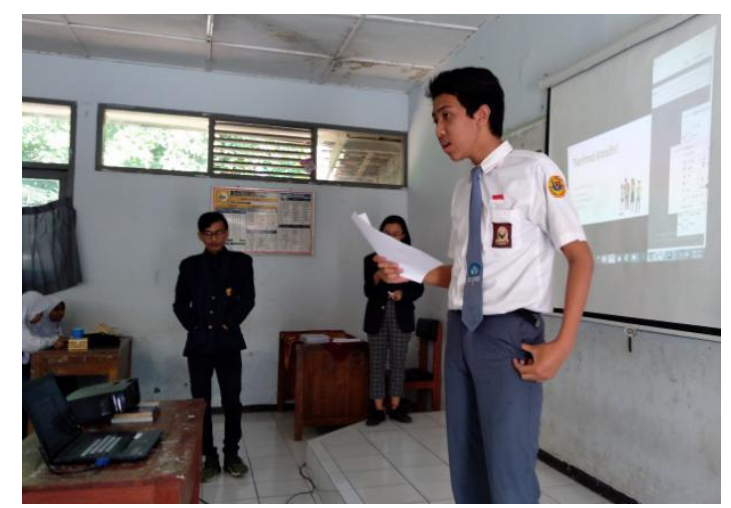

Sumber: tim PPM terintegrasi KKNM Unpad 2019

Dalam kelas kedua, tim PPM terintegrasi KKNM memberikan sosialisasi mengenai E-sport, organisasi dan perkembangannya, keuntungan bisnis dari E-sport. Namun, di atas semua itu, 
tim PPM terintegrasi KKNM Unpad menekankan pula sisi negatif dari E-sport ini, yakni kecanduan dan juga konsumtif. Untuk itu, tim PPM terintegrasi KKNM Unpad mengenalkan tentang pentingnya manajemen waktu dan aplikasi manajemen gadget.

\section{Sosialisasi dalam Kelas Ketiga SMAN 1 Cicalengka: Youtubers}

Youtube adalah situs web video sharing (berbagi video) yang memuat, menonton, dan berbagi video. Youtube didirikan oleh Chad Hurley Steve Chen, dan Jawed Karim pada Februari 2005. Setelah diakuisisi Google, youtube tergabung dengan layanan-layanan google lainnya. Youtube menjadi web yang menarik karena: youtube memberikan layanan gratis baik untuk mengunggah dan menonton video; beberapa video dapat diunduh (download) secara gratis; para pengguna dapat mengakses dan berbagi informasi seputar hal-hal teknis; dapat mengakses video streaming, pengguna dapat mengenalkan dan memasarkan produk; pengguna dapat mengakses video informatif, baik itu video tentang hobi, sejarah, bahkan tutorial pelajaran pun ada; youtube mendukung industri hiburan, misalnya dengan mengunggal trial film, video klip, dan sebagainya; youtube dapat membantu menguatkan branding atau nama lembaga/institusi; terdapat fitur untuk mengetahui respon dan komentar khalayak berupa like dislike bahkan pengguna dapat berkontribusi mendukung video yang diunggah dengan menekan tombol 'subscribe'; dan youtube memfasilitasi pengguna menguasai skill dasar membuat video (Faiqah, Najib, \& Amir, 2016, hal. 261-263).

Youtube kian menarik manakala youtube mampu memberikan penghasilan dan beberapa succes story orang-orang terkenal memperlihatkan salah satu saluran penghasilan mereka dari youtube. Beberapa penghasilan per bulan youtuber berikut menjadi contoh menggiurkan, di antaranya: Dude Perfect sebesar 23 milyar, PewDiePie sebesar18 milyar, Logan Paul Vlogs sebesar 17, CrazyRussianHacker sebesar 11 milyar, Trans TV Official sebesar 3,7 milyar, Kompas TV sebesar 1,5 milyar, Ini Talk Show sebesar 1,4 milyar, Atta Halilintar sebesar 490 jut, Ricis Official sebesar 385 juta, Rans Entertainment sebesar 375 juta, Calon Sarjana sebesar 295 juta, Deddy Corbuzier sebesar 190 juta, Raditya Dika sebesar 165 juta, Fikrifadlu sebesar 140 juta, Jess No Limit sebesar 125 juta, Maell Lee sebesar 95 juta, Najwa Shihab sebesar 90 juta, Tanboy Kun sebesar 85 juta, Milyhya sebesar 75 juta, BrandonKent Everything sebesar 75 juta, Karin Novilda sebesar 65 juta, Ria SW sebesar 60 juta, Edho Zell sebesar 55 juta, Picky Picks sebesar 55 juta, Yoshiolo sebesar 45 juta, dan Aurelie Hermansyah sebesar 45 juta. Penghasilan dari youtube dapat diperoleh dari iklan atau youtube Ads (AdSense), komisi produk dari affiliate marketing, dan jualan produk (Zahir, 2019). 
Namun, di atas masalah penghasilan yang diperoleh dari youtube, prinsip dasar yang menarik dari motivasi youtuber adalah 'berbagi' (sharing).

Melihat youtube sebagai sebuah sarana baru yang cukup menjanjikan dari sisi penyaluran hobi, kreatifitas dan idealisme, dan juga dari sisi pendapatan, tim PPM terintegrasi KKNM Unpad menganggap perlu adanya sosialisasi mengenai youtuber, positif maupun negatifnya, tips maupun regulasinya bagi siswa, dan keterampilan membuat video yang menarik. Terlebih, youtuber juga memiliki pengaruh, terutama bagi para remaja dan pemuda. Remaja memandang, youtuber sebagai hiburan dan kedekatan dalam budaya digital, meski tidak menjadikan mereka panutan. Beberapa remaja menjadikan youtube sebagai media literasi dan memandang youtuber sebagai aktor dan profesional (Ramspott, Fedele, \& Tarrago, 2018, hal. $71)$.

Gambar 2. Simulasi membuat video

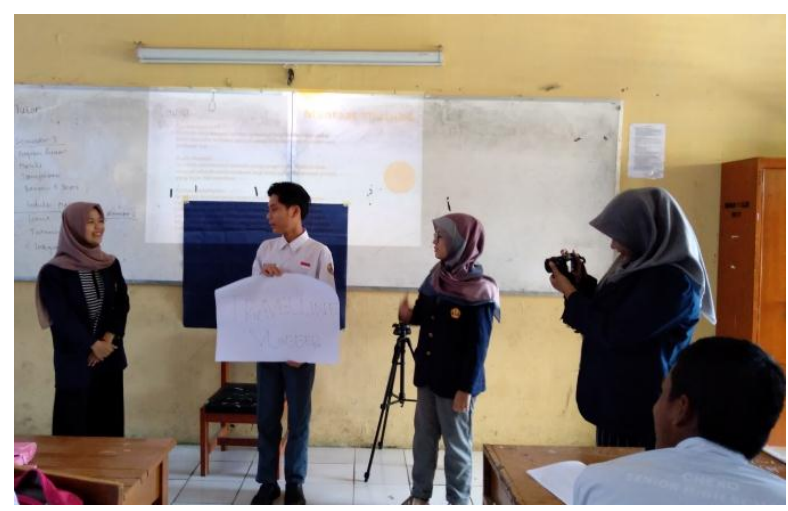

Sumber: tim PPM terintegrasi KKNM Unpad 2019

Di kelas, tim PPM terintegrasi KKNM melakukan simulasi membuat video. Siswa di kelas dibagi menjadi empat kelompok. Setiap kelompok memilih tema yang akan diolah untuk menjadi video. Setelah menentukan tema, siswa mendiskusikan skenario konten video, diikuti dengan pembuatan storyboard secara sederhana. Lalu siswa melakukan shooting video bisa dengan kamera maupun dengan gadget. Pada saat pembuatan video, para siswa diajarkan mengenai aspek pencahayaan agar video tidak gelap atau terlalu terang. Jika di dalam ruangan dan gambar dalam video terlihat gelap, pencahayaan dapat dibantu dengan kertas silver yang mampu memantulkan cahaya secara natural. Para siswa juga dikenalkan dengan angle/sudut pengambilan gambar. Setelah pengambilan video, para siswa dikenalkan dengan editing. Saat ini, banyak fitur aplikasi editing video dalam gadget yang mudah digunakan. Namun, lebih baik lagi jika melakukan editing dengan program komputer sehingga hasilnya bisa lebih 
bagus lagi. Setelah proses pembuatan konten video selesai, para siswa diperkenalkan cara mengunggah ke youtube.

Youtube memang terbuka untuk semua video. Namun bukan berarti seseorang dapat memasukkan video apapun ke dalam youtube. Harus disadari mengenai konsekuensi yang akan diperoleh ketika sebuah video diunggah, yakni respon dari para penonton baik itu berupa rasa suka (like) atau ketidaksukaan (dislike) bahkan hujatan. Untuk itu, alangkah lebih baik jika video yang diunggah itu memiliki konten yang positif, tidak provokatif, tidak menyinggung SARA, tidak mengandung unsur kekerasan dan pornoaksi/pornografi, serta memperhatikan masalah hak kekayaan intelektual (property rights) orang lain dengan tidak sembarangan mengambil video atau bagian video orang lain.

Pada saat pelaksanaan sosialisasi, para siswa di kelas terlihat antusias dan ikut aktif berkontribusi dalam kegiatan mulai dari memilih tema, membuat skenario, storyboard sederhana, dan membuat video.

\section{KESIMPULAN}

Sosialisasi Pengenalan Revolusi Industri 4.0 dan Internet of Things (IoT) bagi Siswa di SMAN 1 Cicalengka telah dilakukan dengan metode eksperimen. Terdapat tiga kelas tempat diselenggarakannya sosialisasi. Dalam masing-masing kelas, tim PPM terintegrasi KKNM memaparkan tentang revolusi industri 4.0 dan IoT berupa artificial intelligence (AI), esport dan youtube. Para siswa di SMAN 1 Cicalengka antusias terhadap kegiatan sosialisasi di kelas. Selain mendengarkan pemaparan materi, para siswa mengerjakan simulasi-simulasi dalam kelompok. Pada kelas pertama dengan tema AI, para siswa selain menerima pemaparan mengenai Revolusi Industri 4.0, artificial intelligence, mereka juga dibekali cara melakukan studi literatur. Hasilnya, rata-rata siswa di kelas tersebut mampu memanfaatkan gagdet untuk melakukan studi literatur. Pada kelas kedua, dengan tema esport, para siswa menerima pemaparan mengenai revolusi industri 4.0, esport dan juga aplikasi manajemen waktu. Pada kelas ketiga, para siswa menerima pemaparan mengenai revolusi industri 4.0, youtube dan tips-tips membuat video singkat.

\section{Gambar 3. Pelaksanaan PPM terintegrasi KKNM Unpad 2019 di SMAN 1 Cicalengka}




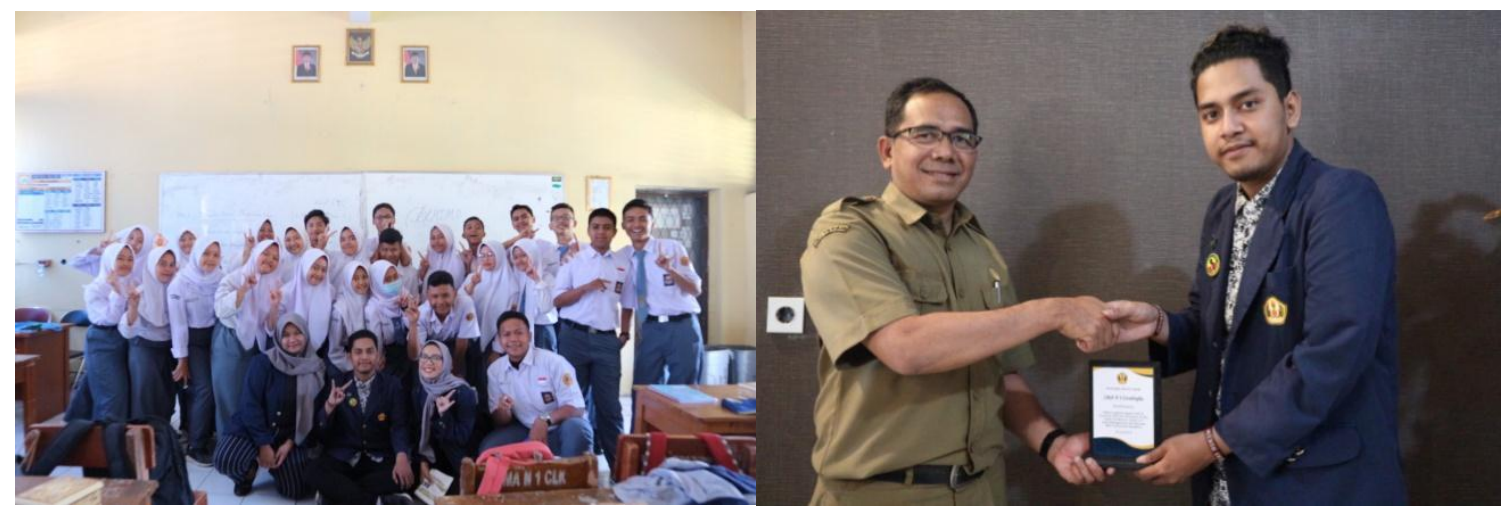

Sumber: tim PPM terintegrasi KKNM Unpad 2019

\section{SARAN}

Sosialisasi yang dilaksanakan masih berupa pengenalan sederhana baik dari sisi materi maupun keterampilan. Tim berharap kegiatan ini mampu menginspirasi para siswa agar lebih kreatif dan senang mempelajari keterampilan-keterampilan IT sehingga menjadi bekal dalam mencari profesi dalam dunia pekerjaan yang ke depannya menuntut kreativitas tinggi. Kontinuitas pembelajaran IT senantiasa harus terus dilanjutkan tanpa meninggalkan esensi dari inovasi sosial dalam revolusi industri 4.0 yakni memanusiakan manusia: bahwa semua perkembangan dan kemajuan sosial yang berlangsung seyogyanya adalah untuk memenuhi kebutuhan manusia. IT ada untuk membuat kehidupan manusia lebih baik lagi.

\section{UCAPAN TERIMA KASIH}

Tim PPM terintegrasi KKNM Unpad mengucapkan terima kasih yang sebesar-besarnya kepada Rektor Universitas Padjadjaran yang telah memberikan kesempatan dan kepercayaan bagi tim untuk menjalankan penelitian dan kegiatan pengabdian pada masyarakat dalam skema Hibah Internal Unpad (HIU) tahun 2019. Terima kasih kami sampaikan pula kepada Kepala Sekolah SMAN 1 Cicalengka beserta staf pengajar dan para siswa yang berkenan berkontribusi dalam kegiatan PPM terintegrasi KKNM Unpad. Kesediaan dan kesempatan waktu yang dialokasikan oleh SMAN 1 Cicalengka merupakan sebuah kerjasama yang kami hargai dan hormati sepenuhnya, manakala kegiatan PPM terintegrasi KKNM ini berlangsung seiring dengan padatnya agenda SMAN 1 Cicalengka menyiapkan pembelajaran awal semester. Tim berharap, kegiatan ini dapat memberikan kontribusi positif baik itu bagi kalangan akademika, mitra PPM, maupun pada masyarakat secara umum.

\section{DAFTAR PUSTAKA}


Auditor, T. I. (2017). Perspektif dan Pandangan Global Keerdasan Buatan (AI). The INstitute of Internal Auditor.

Ayu, N. A. (2018). Peluang Social Innovation dalam Revolusi Indtri 4.0: Bagaimana perkembangannya di Indonesia. Yogyakarta: Forbil Institute.

Berente, N., Gu, B., Recker, J., \& Santhanam, R. (2019, NOvember 15). Managing AI. MIS Quarterly, 1-5.

Buhr, D. (2017). Social Innovation Policy for Industry 4.0. Jerman: friedrich Ebert Stiftung.

Faiqah, F., Najib, M., \& Amir, A. S. (2016). Youtube sebagai sarana Komunikasi bagi Komunitas Makassarvidgram. Jurnal Komunikasi KAREBA, 259-272.

Handoyo, R. E. (2019, Januari 7). 7 Fasilitas Sehari-hari ini ternyata sudah GUnakan Kecerdasan Buatan. Dipetik November 2019, 6 , dari IDN Times: https://www.idntimes.com/tech/gadget/ribka-eleazar/fasilitas-keseharian-yangsudah-menggunakan-artificial-intelligence/full

Huk, T. (2018). The Social Context of the Benefits Achieved in eSport. The New Educational Review, 160-169.

Khan, A., \& Turowski, K. (2016). A Perspective on Industry 4.0: From Challenges to Opportunities in Production System. International Conference on Internet of Things and Big Data (IoTBD), (hal. 441-448).

Kim, S. H., \& Thomas, M. K. (2015). A Stage Theory Model of Professional Video Game Players in South Korea: The Socio-Cultural Dimension of the Deevlopment of Expertise. Asian Journal of Information Technology, 14(5), 176-186.

Liao, Y., Loures, E. R., Deschamps, F., Brezinski, G., \& Venancio, A. (2018). The Impact of the fourth Industrial Revolution: A Cross-Country/region Comparison. Production, $1-18$.

Manda, M. I., \& Dhaou, S. B. (2019). Responding to the Challenges and Opportunities in the 4th Industrial Revolution in Developing Countries. ICEGOV, 244-253.

Morra, R., Arman, H., \& Mousa, S. (2017). The Fourth Industrial Revolution (Industry 4.0): A Social Innovation Perspective. Technology Innovaion Management Review, 7(11), $12-21$.

Nugraha, D. (2018, Oktober). ristekdikti. Dipetik oKtober 04, 2019, dari https://puspiptek.ristekdikti.go.id 
Prasetyo, B., \& Trisyanti, U. (2018). Revolusi Industri 4.0 dan Tantangan Perubahan Sosia. SEMATEKSOS 3 "Strategi Pembangunan Nasional menghadapi Revolusi Industri 4.0", (hal. 22-27).

Ramspott, S. A., Fedele, M., \& Tarrago, A. (2018). Youtubers' social functions and their influence on pre-adolescence. Media Educatio Research Journal, 71-79.

Rojko, A. (2017). Industry 4.0 Concept: Background and Overview. iJIM, 11(5), 77-90.

Zahir, F. (2019, November 2). Berapa Penghasilan Youtuber Sebenarnya? Dipetik November 6, 2019, dari Ruang Laptop: https://ruanglaptop.com/berapa-penghasilan-youtuber/ 